\title{
A Corpus-Based Contrastive Study of HEART Metaphor in Chinese and English
}

\author{
Shifang Zhou \\ Xiangyong Jiang \\ Foreign Languages College \\ Jiangxi Normal University \\ Nanchang, China
}

\begin{abstract}
This paper analyzes universalities and variations of HEART metaphor via qualitative and quantitative analysis of data retrieved from two authoritative, general, and monolingual corpora-Center for Chinese Linguistics (CCL) and Corpus of Contemporary American English (COCA) in Chinese and English. Results reveal that the universal bodily experience is responsible for the largely shared source domains for HEART metaphor (e.g. CONTAINER, OBJECT, LIVING ORGANISM, etc.) which justifies the universality of conceptual metaphor. However, HEART metaphor in Chinese is richer than in English due to the difference between Western dualism and ancient Chinese philosophy. Besides, the shared metaphor like OBJECT display variations in detail, and unique source domains are used for a particular culture (GAS in Chinese and MECHANICS in English). The traditional Chinese medicine can account for the unique source domain of GAS in Chinese and the other variations can be ascribed to the different social-cultural history in English and Chinese.
\end{abstract}

Keywords: HEART metaphor, corpus-based method, contrastive study

\section{Introduction}

The "restless heart" in our chest has always been a great enigma and mystery of human life since the dawn of human cultural history. The heart is central to our life because it is simultaneously "the organ and symbol of the most basic and yet crucial manifestations of life" (Doueihi, 1997: 17). The Chinese ancients regarded the heart as the master of human organs; Høystad (2007: 7) pointed out that "the heart is the main symbol of what it means to be a human being". The importance of the heart is self-evident from these points of view. The scientific definition of the "physical heart" is that it's the internal organ that pumps blood for circulation inside the body. Defined in terms of bodily functions, this definition should be the same among human beings of different cultural or ethnic backgrounds. However, this paper instead focuses on the cultural conception of the "mental heart", which may vary across different cultures or even within one culture across different periods of its history.

Body-related words are commonly seen in English and Chinese. Johnson (2007: ix) argues that "meaning grows from our visceral connections to life and the bodily conditions of life". Our mind is embodied in the profound sense that the very structure of our thoughts come from the nature of our body (Lakoff and Johnson, 1999). As the most important human organs, the heart is taken as the reference in human's interaction and experience with the external world. As a result, a large number of heart-related words can be found in our daily languages.

Metaphor is not merely a figure of speech, but also a figure of thought. Lakoff \& Johnson (1980) were the first to present a cognitive analysis of conceptual metaphors, which was then known as Conceptual Metaphor Theory (henceforth CMT). Metaphor is pervasive in everyday life, not just in language but in thought and action (Lakoff \& Johnson, 1980: 4). It is a cognitive phenomenon that is all-pervasive to our thinking. "Many concepts, especially abstract ones, are structured and mentally represented in terms of metaphor" (Gibbs, 1999b: 145). From a cognitive perspective, metaphors function by mapping the meaning structure of a more concrete source domain onto the conceptual structure of a more abstract target domain in order to facilitate understanding of this second domain in some way. Abstract concepts "are defined by systematic mappings from bodily-based sensorimotor source domain onto abstract target domains" (Johnson and Rohrer, 2007: 37). And it is metaphor that "makes it possible to extend bodybased meaning and inference into abstract thought" (Johnson, 2007: 176-177). Metaphor plays an essential role in shaping our understanding of a daily event and can reveal the hidden sides of one's mind and culture.

The study of the metaphorical conceptions of "heart" based on linguistic analysis can add to the general understanding of human cognition in diverse cultures, especially with regard to cultural changes and cultural differences in viewing how the mind is related to the body, and provide "an intriguing glimpse of how different cultures believe the body and the mind work" (Small 1997: 131; see, also, Sharifian et al. 2008a). 
In recent years, scholars at home and abroad have investigated and analyzed "heart" and its related expressions from different perspectives and levels.

Lakoff \&Johnson (1980) studied mind-related metaphors in English, such as "THE MIND IS A BRITTLE OBJECT" and "THE MIND IS A MACHINE". Due to the limited level of Science in the past, people regarded "heart" as the organ of thinking, so there is some internal connection between "heart" and "mind". In these metaphors, "MIND" can be replaced by "HEART". Niemier (2000) explored the relationship between metaphor and metonymy from the cognitive perspective by collecting data about heart in the dictionary. In his early research, she devoted herself to the cultural model of "HEART AS THE LOCUS OF EMOTION". She further proposed that English contains many heartrelated metonymy and metaphor that refer to emotion. Niemeier (2008) discussed the nearly absolute dichotomy between head and heart expressions in present-day English, pointing out that the "heart" is the seat of emotion, while the "head/brain" is the seat of rationality and intelligence. He further distinguishes four types of HEART metaphors, such as "HEART AS THE LOCUS OF A PERSON'S FEELINGS" "HEART AS THE PERSON AS A WHOLE" "HEART AS AN OBJECT OF VALUE" "HEART AS A CONTAINER". Niemeier believed that the "head-heart" dichotomy in the English language was mainly due to the overwhelming influence of Cartesian philosophy. Yu (2007) systematically studied the conceptual metaphor of "THE HEART IS THE RULER OF THE BODY" from the perspective of cognition, and believed that ancient Chinese philosophy had an important influence on the conceptualization of "HEART". By studying the origin of the conceptualization of Chinese "HEART", he proposed that "heart" was traditionally regarded as the physiological center of the human body and the cognitive center, and then proposed "THE HEART IS THE RULER OF THE BODY" and "THE RULER IS THE HEART OF THE COUNTRY" metaphor. He regarded the "heart" as the organ that governs the body (including the brain) and analyzed it in detail. However, his research mainly focuses on the metaphor of "heart" in Chinese. There are few examples in English. It is like introducing Chinese philosophy to Western readers. Pritzker (2007) explored the heart and brain metaphors used in the meaning-making efforts of 49 Chinese individuals diagnosed with depression. Her findings showed that 45 out of $49(92 \%)$ patients referred to the heart to express thinking and feeling, 18 of the 45 (37\%) also referred to the brain to express thinking and feeling, and 4 out of 49 referred to neither the heart nor the brain. Based on this finding, Pritzker argues that cultural understandings of the self can be multiple.

There are not only direct studies on the expression of "HEART" in English, but also comparative studies based on two languages. On the basis of natural semantic metalanguage, Goddard (2008) compared the meaning of "HEART" in English and "Hati" in Malay from the perspective of semantics. He explained these words by listing some simple general concepts. In addition, he explained some common collocations of "heart". Foolen (2008) compared the HEART metaphor in English and Dutch. In his research on the conceptualization of the Dutch "heart", he found that Dutch and English had a similar development, that is, Middle Dutch still maintained a cardiocentric view, but this view no longer exists in today's Dutch.

Some Chinese scholars have also paid attention to the linguistic expressions of Chinese "heart". Wang (2001) explored the mental structure of the spatial metaphor of "heart" in Chinese. He divided the HEART metaphor into three types, namely one-dimensional, two-dimensional, and three-dimensional. Xiang (2010) interpreted the main conceptual metaphor of "THE HEART IS THE RULER OF THE BODY" in ancient Chinese philosophy, presenting the mapping between the mental power of "heart" and the political power of "emperor". Hou (2001) explored the cultural connotation of Chinese "heart". She believes that the connotation of Chinese "heart" is influenced not only by Chinese traditional culture but also by Buddhist culture, which embodies the holistic view and humanistic spirit of Chinese people. A dynamic relationship system among human, society, and nature was formed by taking the "heart" as the center.

In addition to the studies of Chinese "heart", there are also some comparative studies of the HEART metaphors between Chinese and English conducted by Chinese scholars. Qi (2003) made a comparative analysis of English and Chinese HEART metaphors by collecting data from dictionaries, trying to reveal their similarities and differences. Although the results of this paper did not realize his original intention, he opened up a new way to study the HEART metaphor, that is, to compare the HEART metaphor in English and Chinese. Wu (2004) made a further comparison between the spatial metaphor and ontological metaphor of "heart" in English and Chinese. He put forward the zerodimensional spatial metaphor of "heart" in both English and Chinese, proving that metaphor is an important tool for human beings to understand the world. Qi \& Qin (2004) analyzed HEART metaphors in English and Chinese from the perspective of Image Schemas and Conceptual Metaphor Theory. They further explored how the Chinese and western culture motivated the language expressions of "heart". Zhang (2005) showed how the polysemous network of "heart" is derived based on different cognitive processes. He divided the meanings of "heart" into nine categories and investigated compound words containing "heart" by selecting data from English and Chinese dictionaries. Zhang (2006) 
further analyzed "heart" in English and Chinese. He believed that the differences between them lie in cultural factors and the language itself. By comparing the semantic categories of "heart" in English and Chinese, Xie (2007) revealed the similar cognitive processes of human beings in different languages, that is, people all understand abstract emotions, psychology, thinking based on the metaphorization of their body experience. Languages can produce new meanings in people's understanding of the world. Qi \& Wang (2007) constructed six metonymic frameworks and two metaphorical frameworks so as to find out the similarities and differences of Chinese and English "heart". They also discussed the cognitive mechanism of meaning production and expansion of "heart" in the two languages.

The above researches have made significant contributions to the study of the HEART metaphor. Domestic and foreign scholars have analyzed the language expression of "heart" from many aspects, including monolingual research, bilingual comparative study, and cognition-based study. However, the existing researches on the HEART metaphor are still far from satisfactory. First, a comparative analysis of HEART metaphors between different languages, especially the cross-cultural metaphorical variation concerning HEART between Chinese and English, has not been fully investigated yet. Second, as for the research methodology, the previous research mainly extracts some examples from English and Chinese dictionaries. The evidence that cognitive linguistics should rely on is not only introspective but also includes more empirical evidence such as the results of psycholinguistic tests, language acquisition data, diachronic and synchronic data (either elicited from native speakers or corpus data) (Brdar-Szabo, Rita, \& Mario Brdar, 2012). Though some of the above studies have explored the similarities and differences between HEART metaphors in two different languages, they did not supply useful and efficient corpora. Therefore, they fail to be representative, comprehensive, and convincing.

In this paper, we attempt to conduct a systematic corpus-based analysis of HEART metaphors in English and Chinese from the perspective of CMT. Both the quantitative and qualitative methods are used to analyze data from two corpora. The two corpora are respectively Center for Chinese Linguistics, Peking University (henceforth CCL), and Corpus of Contemporary American English (henceforth COCA).

For this study, my goal is twofold: firstly, I will discuss how the internal organ of the heart is metaphorically employed in Chinese and English languages to conceptualize human experiences such as emotions and/or workings of the mind, and further find their similarities and differences; Secondly, factors that appear to account for the observed similarities, as well as differences of the various conceptualization of HEART, will be explored. Our study is novel on several accounts. Different from previous studies, this study is based on an extensive analysis of HEART metaphors in English and Chinese from two large corpora. The empirical corpus-based methodology can get rid of the limitations of intuition as much as possible and further ensures the objectivity, comprehensiveness, and reliability of data by providing authentic language materials. Besides, this paper not only discusses the similarities and differences in how people conceptualize HEART through metaphor but also explains the reasons for the similarities and differences between Chinese and English HEART metaphors.

The structure of this paper is as follows: After the introduction, Section 2 describes the methodology of the research. Section 3 enters into some quantitative and qualitative analyses of the corpus data. Section 4 sums up the main findings of the studies.

\section{Method}

\subsection{Research Questions}

1) What are the universalities of the HEART metaphor between American and Chinese?

2) What are the variations of the HEART metaphor between American and Chinese?

3) What are the factors accounting for the universalities and variations?

\subsection{Data Source}

The data collected and served as the basis for the following analysis stems from two large-scale corpora, Center for Chinese Linguistics, Peking University (henceforth CCL), and Corpus of Contemporary American English (henceforth COCA). The links for the online free search engines are as below: http://ccl.pku.edu.cn:8080/ccl_corpus/ (CCL) and https://www.english-corpora.org/coca/ (COCA).

CCL is a sizeable online corpus containing 700 million Chinese characters, developed by the Center for Chinese Linguistics, Peking University. It is composed of two subcorpora: the Ancient Chinese Corpus and the Modern Chinese Corpus. The data collected in this paper only comes from the Modern Chinese Corpus. Apart from the extensive collection, it has comprehensive coverage of data from newspapers, literature works, translation, academic works, movies, TV programs, internet to spoken materials, etc. CCL offers free online access for users. It is widely used by researchers on language, Chinese education, and language use in society. 
COCA is the most extensive free English corpus and the first large-scale balanced American English corpus. It was founded by Professor Mark Davies at Brigham Young University and officially launched in 2008. COCA consists of 450 million words of text, which includes five different genres: spoken language, novels, popular magazines, newspapers, and academic articles. Each genre accounts for $20 \%$ of the corpus. The five genres are expanding at an annual rate of 200 million words to ensure the timeliness of corpus content from 1999 to 2012. The corpus is updated once or twice a year. Therefore, COCA is considered to be the most appropriate English corpus to observe the current development and change of American English.

Both of the corpora are general and monolingual. "General" means that the data is not restricted to any specific genre or style, but data from all kinds of fields. As for monolingual, it means that the data is from a specific language, such as American English or Chinese. Therefore, the reliability and comparability of data are assured.

\subsection{Data Collection}

The main problem that needs to be focused on is how to identify and extract the HEART metaphor from the corpus data. But before that, it is necessary to explain how we search on the two online corpora.

In this paper, all the examples are extracted by directly searching out the Chinese character “心 xin (pronounced close to shin)" in CCL and "heart" in COCA. The data in this paper are not limited to any genre. In consideration of the length of the paper, we select one sample every 200 at random and copy that with a separate document. As a result, 3000 samples of "xin" and 3000 samples of "heart" are collected for further categorization and analysis.

Moreover, in order to see the general situations of the metaphorical use of "heart" in the two languages, the number of HEART metaphors in the two corpora is calculated by putting samples got above into different types of metaphors.

\subsection{Identification of Metaphor}

After extracting data of “心 xin” from CCL and "heart” from COCA, the next step is to identify the HEART metaphor among these linguistic examples. In order to increase the credibility of the identification of metaphor, we adopted the method of MIP (Metaphor Identification Procedure). It is proposed by Pragglejaz Group (2007) in order to identify the metaphorical words in discourse. The main points of MIP can be summarized as follows. 1) Read the entire text to understand its general meaning. 2) Divide the whole text into several lexical units. 3) Find out the contextual meaning and lexical meaning of each lexical unit. 4) Compare the contextual meaning and the lexical meaning of each lexical unit. If the contextual meaning is in contrast with the lexical meaning, but can still be understood in terms of it, this lexical unit is metaphorical. Otherwise, it is literal. In order to illustrate MIP, we can use the words in bold in the following sentence as an example.

(1) Opening my heart was how I was caring for myself.

A reading of the whole sentence, step 1, reveals that it has something to do with the open status of the heart that may help people show their emotions.

In step 2, the lexical units among the above bold words are identified as follows. Slashes are used here to indicate boundaries.

\section{Opening/my/heart}

In step 3, we outline our decisions for each lexical unit and then determine whether the lexical unit is metaphorically used in the context of this text in step 4.

\section{Opening}

(a) contextual meaning: In this context, "opening" is the progressive tense of the verb "open". Here it means the action of opening one's heart.

(b) basic meaning: One of the basic meanings of "open" refers to that if you open something such as a door, window, or lid, or if it opens, its position is changed so that it no longer covers a hole or gap.

(c)contextual meaning versus basic meaning: The contextual meaning is closely related to the literal meaning.

(d) metaphorically used? No.

\section{My}

(a) contextual meaning: In this context, "my" indicates the possession of one's own heart. 
(b) basic meaning: As an adjectival possessive pronoun, "my" indicates that something belongs or relates to himself or herself.

(c) contextual meaning versus basic meaning: The contextual meaning is closely related to the literal meaning.

(d) metaphorically used? No.

\section{Heart}

(a) contextual meaning: In this context, "heart" indicates that it is a container with a lid and is being opened now.

(b) basic meaning: One of the basic meaning of "heart" refers to the organ in your chest that pumps the blood around your body.

(c) contextual meaning versus basic meaning: The contextual meaning contrasts with the basic meaning, but can be understood by comparison with it. We can understand the "heart" here by conceptualizing it as a container with a lid and can be opened.

(d) metaphorically used? Yes.

To sum up, one out of the three bold words is recognized as metaphorical. This sentence contains HEART IS A CONTAINER metaphor. Our explanation of MIP to lexical units is intended to demonstrate how the procedure works and how the researchers make decisions in judging whether the examples in the corpus are used metaphorically. In order to increase the data credibility, this paper conducts three times throughout check repeatedly.

\section{Results}

\subsection{Frequency of HEART Metaphor in CCL and COCA}

In the first step, we identify and extract the HEART metaphor utilizing the method of MIP in the two large corpora. In sum, there are 1190 English HEART metaphor in COCA and 1483 Chinese HEART metaphor in CCL. Specific data are shown as follows.

\section{Table 1: The number of sentences containing HEART metaphor}

\begin{tabular}{llll}
\hline & Total sentences & HEART-metaphor sentences & Percentage \\
\hline HEART (in COCA) & 3000 & 1190 & $39.67 \%$ \\
“心 xin” (in CCL) & 3000 & 1483 & $49.43 \%$ \\
\hline
\end{tabular}

According to the data, it can be found that both English and Chinese have a significant number of HEART metaphors, but the frequency of “心 xin" metaphor in CCL is higher than HEART metaphor in COCA. In other words, HEART metaphor is a pervasive phenomenon both in CCL and COCA, but conceptual metaphors denoting HEART is more pervasive in Chinese than English.

\subsection{Universality and Variation of the Conceptual Metaphors Denoting HEART in CCL and COCA}

After the identification of the HEART metaphor in CCL and COCA, it can be seen that HEART metaphors are relatively abundant in English and Chinese. In order to find out how similar and different they are, we draw up a list of the ten most frequently occurring conceptual metaphors in CCL and COCA. The detailed data can be shown in table 2 and table 3 as follows. 
Table 2: The ten most frequent Chinese conceptualizations of HEART in CCL

\begin{tabular}{llll}
\hline No. & Metaphor & Tokens & Percentage \\
\hline $\mathbf{1}$ & CONTAINER & 582 & $39.24 \%$ \\
$\mathbf{2}$ & OBJECT & 461 & $31.09 \%$ \\
$\mathbf{3}$ & LIVING ORGANISM & 292 & $19.69 \%$ \\
$\mathbf{4}$ & LIQUID & 98 & $6.61 \%$ \\
$\mathbf{5}$ & MUSICAL INSTRUMENT & 12 & $0.81 \%$ \\
$\mathbf{6}$ & FIRE & 12 & $0.81 \%$ \\
$\mathbf{7}$ & GAS & 10 & $0.67 \%$ \\
$\mathbf{8}$ & AGRICULTURE & 10 & $0.67 \%$ \\
$\mathbf{9}$ & LIGHT & 3 & $0.20 \%$ \\
$\mathbf{1 0}$ & OTHERS & 3 & $0.20 \%$ \\
& SUB-TOTAL & 1483 & $100 \%$ \\
& TOTAL & 1483 & $100 \%$ \\
\hline
\end{tabular}

Table 3: The ten most frequent American conceptualizations of HEART in COCA

\begin{tabular}{llll}
\hline No. & Metaphor & Tokens & Percentage \\
\hline $\mathbf{1}$ & CONTAINER & 464 & $38.99 \%$ \\
$\mathbf{2}$ & OBJECT & 428 & $35.97 \%$ \\
$\mathbf{3}$ & LIVING ORGANISM & 198 & $16.64 \%$ \\
$\mathbf{4}$ & MECHANICS & 22 & $1.85 \%$ \\
$\mathbf{5}$ & MUSICAL INSTRUMENT & 18 & $1.51 \%$ \\
$\mathbf{6}$ & LIQUIID & 16 & $1.34 \%$ \\
$\mathbf{7}$ & FIRE & 12 & $1.01 \%$ \\
$\mathbf{8}$ & SPORTS GAME & 12 & $1.01 \%$ \\
$\mathbf{9}$ & BOOK & 8 & $0.67 \%$ \\
$\mathbf{1 0}$ & OTHERS & 12 & $1.01 \%$ \\
& SUB-TOTAL & 1190 & $100 \%$ \\
\hline
\end{tabular}

As table 2 and table 3 showed, different source domains are mapped into the same target domain, the heart. That is, the mapping converge on one and the same target from different angles or different source domains, each mapping one specific aspect or function onto the "blended space" of global conceptualization of the heart, and each also placing it in a new light. While the source domains are all different and are not necessarily consistent with each other, there is some sort of coherence among them. The top three Chinese source domains are the same as that of the English, which in descending order are CONTAINER, OBJECT, and LIVING ORGANISM.

\subsubsection{Universality of the Conceptual Metaphors Denoting HEART in CCL and COCA}

Though English and Chinese are two completely different language systems, the way they conceptualize the concept of HEART cross with each other. A glance at table 2 and table 3 makes it evident that the metaphorical conceptualizations of HEART are close to that of American: six out of the ten top metaphors in the respective data sets are shared (CONTAINER, OBJECT, LIVING ORGANISM, LIQUID, MUSICAL INSTRUMENT, FIRE).

The CONTAINER metaphor is a very popular conceptualization, as it surfaced as the most frequent metaphor in both corpora, accounting for $38.99 \%$ of the COCA data and $39.24 \%$ of the CCL data. "We are physical beings, bounded and set off from the rest of the world by the surface of our skins and we experience the rest of the world as outside us. Each of us is a container with a bounding surface and in-out orientation." (Lakoff \& Johnson, 1980: 26)

Reddy (1979) proposed the conduit metaphor. The conduit metaphor focused on the attention of the all-pervasive container conceptualization. Both the message and the words in which it is "packed" are seen as containers, which we unpack and out of which we take the contents, i.e. the meaning. The same applies to the human body and its major parts. Thus the head, the heart, the chest may all been seen as containers.

In the HEART IS A CONTAINER metaphor, HEART is conceptualized as a container, mental and emotional things are contents in the container. The mental capacity is the physical capacity of the container. The following table 4 and examples will show some of the different types of containers that "heart" is conceptualized as depending on the aspects focused upon in conceptualization. 
Table 4: Ratio of sample "HEART and xin as a CONTAINER"

\begin{tabular}{llllll}
\hline CONTAINER & LID & CONTENT & DEPTH & HOUSE & Sub-total \\
\hline HEART & 65 & 150 & 236 & 13 & 464 \\
“心 xin” & 199 & 51 & 327 & 5 & 582 \\
\hline
\end{tabular}

The HEART container can be seen as covered by a lid which may be opened or closed. When opened, there is free access to the speaker's feelings or emotions; when the heart is conceptualized as closed, there is no entry to the speaker's emotional world. In this case, metaphorical expressions about "HEART" and "心 xin" as a CONTAINER WITH A LID are abundant in English and Chinese, such as to open one's heart, to close one's heart to something, 开 心(lit. open the heart; “joyful”), 关心(lit: close the heart; "be concerned about”). Some example sentences are as follows:

(1) a. 我们将陆续推出介绍各申办城市的报道, 试图解答这些读者[关心]的问题。

We will continue to publish reports on the cities that bid to host the city, trying to answer the questions that these readers are concerned about (lit. close the heart).

b. A mother should open her heart to her children, not make them fight their way in.

In Chinese, a commonly-used compound for "be concerned about something or someone" literally means "close the heart" (关心 guanxin). In (1a), the questions that the readers are concerned about are their inner thoughts and emotions that are kept in the HEART container with a covered lid. People can answer these questions only when the readers speak out their real thoughts. In (1b), what the mother should do is to open her heart to her kids so that her kids will understand her real thoughts and emotions and avoid fighting.

An important characteristic of a container is that it has a physical capacity, that is, its storage is limited and it can only contain a certain number of things or certain amounts of the substance. So the HEART container can be full or empty. In the full situation, it will be overflow or pour something out, such as a heart overflowing with gratitude, 心满意足(be fully satisfied and content); in the empty situation, the opposite kind of movement will happen, that is, it will take or tolerate something, such as filled my heart with joy, 虚心'(lit. empty-heart; “modest”), etc.

(2) a. 她满[心]欢喜地跟着表姐去了。

She followed her sister, full of joy (lit. full-heart-merry-happy).

b. I'd poured out my heart for the kids and parents, and they'd responded.

Example (2a) describes the emotional state of the girl, that is, she is very glad to follow her sister with her heart full of joy. In (2b), the HEART container is full of emotions but this person does not wish the overflow take place, so she chose to tell his kids and parents about her feelings to avoid it.

The "HEART" and "XIN" can also be seen as a CONTAINER WITH GREAT DEPTH. This type of HEART container is conceptualized as having a depth and a bottom representing the location where one's innermost feelings are stored, as in deep in my heart, 内心深处(in the depth of one's heart).

(3) a. 研究室的所有年青教师, 更是把悲痛强压[心]底, 他们知道, 对导师的最好的安慰, 就是早日做出成绩 来。

All the young teachers in the research laboratory put their grief to the bottom of their hearts. They knew that the best consolation for their tutors was to make achievements as soon as possible.

b. If you can clarify this, I would appreciate it from the bottom of my heart.

The bottom is where more dormant thoughts and emotions are "settled" or "buried". If people want to suppress feelings and thoughts, they will "press" them down, or even "bury" them beneath the bottom. In (3a), the young teachers feel grieved and they store that feeling at the bottom of their hearts. In this way, they can keep this true feeling a secret and turn grief into strength. In (3b), the appreciation from the bottom of one's heart means that the person would be very grateful for the clarification.

As shown in table 4, the "heart" is also conceptualized as a "house", which a special case of a container. The "heart" is the place that stores thoughts and feelings or houses mental activities and processes. The heart-house, with chambers or 
rooms inside, is the dwelling place of soul, the home of blood, and the storehouse of secrets, memories, or lived experience.

(4) a. 另一个人的影子不知不觉地印进春玲的脑海, 继之闯进她的[心]房。

Another person's appearance unconsciously entered Chunling's mind, and then burst into her heart (lit. heart-house).

b. Cupid knocks at the door of a human heart;

In (4a), the "heart" is conceptualized as a "house". When things break into the "heart-house", they will linger in people's minds. In (4b), Cupid is the God of love. So his knocking at the door of a human heart implies that this person has fallen in love.

OBJECT as a source domain for HEART ranks second in both CCL and COCA. In the HEART IS AN OBJECT metaphor, "object" is actually the superordinate of "container", since a container is necessarily an object whereas the reverse may not be true. Attributes and characteristics of the object are mapped on the "heart" and “心 xin", as a result, the metaphorical "heart" expression also has the characteristics and properties that a solid object hold. Here the "heart" has a variety of qualities of physical objects, including having solid state, having property, and having features.

Table 5: Ratio of sample "HEART and xin as an OBJECT"

\begin{tabular}{llllll}
\hline SOLID STATE & Movement & Fragileness & Weight & Shape & Sub-total \\
\hline HEART & 12 & 152 & 20 & 36 & 220 \\
“心 xin” & 195 & 7 & 11 & 76 & 289 \\
\hline PROPERTY & Hardness & Temperature & Material & & \\
\hline HEART & 12 & 23 & 12 & & 47 \\
“心 xin” & 4 & 32 & 5 & & 41 \\
\hline FEATURES & Color & Quantity & Flavor & Quality & \\
\hline HEART & 52 & 76 & 4 & 29 & 161 \\
“心 xin” & 7 & 65 & 32 & 27 & 131 \\
\hline
\end{tabular}

As a solid object, "heart" and "xin" hold the attributes as a movable object, a frail object, a weighable object, and an object with multiple shapes.

The object owns the property of movement. Through metaphorical mapping, the "heart" and "xin" can work as movable objects. For example:

(5) a. 或许是命里有缘, 每次到陕北, 都能遇上一些让我彻底动[心]的剪纸人。

Maybe it's fate in my life, because every time I go to northern Shaanxi, I can meet some paper-cut people who captivate me completely (lit. completely move my heart).

b. My heart lifted because it was Dean seeing something good in his brother.

In (5a), when someone's "xin" moved, he has fallen in love with something. In (5b), the "heart" was lifted means that the person felt happy. It shows the orientational metaphor of HAPPY IS UP, SAD IS DOWN.

An object can be strong and frail. In this case, the "heart" and "xin" object are frail objects and can be broken and injured under some circumstances.

(6) a. 碗碎了, 她的[心]也碎了。

The bowl is broken, so is her [heart].

b. I'm so sorry to hear about your broken heart and the death of your father.

In (6a), the broken bowl symbolizes the person's broken heart. It means that she is very sad. In (6b), the person's heart was broken for her father's death. In these cases, the broken heart is used to describe people's sadness.

In addition to the above mentioned two attributes as an object, the "heart" and "xin" are also viewed as weighable objects, including being weight or light.

(7) a. 不过，魏国毕竟强大，他无时无刻不在威胁寡人，你们万不可掉以轻[心]。

However, the State of Wei is powerful after all, and he is threatening me all the time. You must not treat it lightly(lit. light-heart). 
b. I have a heavy heart when I think of their families and their grief.

People with a "light heart" usually are in a cheerful or joyous mood. "Light heart" could nearly fly away, thus lighthearted people are inclined to be not careful. In (7a), if people treat things with a "light heart", they will not take it seriously and they are easy to make mistakes. In (7b), when people have a heavy heart, they will feel heavy. In other words, they will feel unhappy and low in mood.

The "heart" and "xin" objects also have different shapes, which may be big and small, thin and thick, high and low, etc.

(8) a. 不要到人多的地方, 保持低调, 对来路不明的邮件和包裹要小[心]谨慎。

Don't go to crowded places, keep a low profile, and be careful with(lit. small heart) mails and parcels of unknown origin.

b. She had such a huge heart for animals and she loved her family so much, especially her son.

In (8a), people with a small heart in Chinese are very careful and cautious. In (8b), people with a huge/big heart are always friendly, altruistic, empathetic, and give help generously.

The "heart" and "xin" objects also have properties of hardness, temperature, and can be made of different materials.

The "hard" objects leave us the impression that they are strong, tough, and inflexible; while the "soft" objects give us the impression of frailness, tenderness, and flexibility. In other words, people with a "hard heart" are not easily touched and have no sympathy for others. By contrast, people with a "soft heart" refer to those who are easily touched and sympathetic.

(9) a. 这次却不是由于她[心]软, 而是有人阻止了她。

This time it wasn't because she was being soft-hearted again, it was someone who stopped her.

b. The ruin of sinners is their walking after a hard and impenitent heart.

"Soft heart" in (9a) means sympathetic, which is in contrast with "hard-heart" in (9b) which means not sympathetic at all.

The objects can have different temperatures in different situations. Therefore, the "heart" and "xin" object are also viewed as possessing the property of warmth and coldness. The coldness usually leaves us negative feelings. People with a "cold heart" usually have no sympathy or care for others. In contrast to it, people with a "warm heart" are usually friendly and affectionate.

(10) a. 热[心]的球迷们不断为双方鼓劲呐喊。

The enthusiastic (lit. hot-heart) fans kept cheering for both sides.

b. One family has a tradition of choosing movies that warm the heart.

In (10a), the fans with hot hearts are full of enthusiasm to cheer for their team. In (10b), the family tends to warm their member's hearts by watching a movie together. They can show their care for others in this way.

The "heart" and "xin" object can be made of different materials, such as steel, stone, gold, etc.

(11) a. 反复思忖，王吉元下了铁[心], 要将这消息禀报闯王，愈快愈好。

Thinking over and over again, Wang Jiyuan made up his mind to(lit. iron-heart) report the news to Chuang Wang as soon as possible.

b. But, uh, he's got a heart of gold. And he likes you.

In (11a), the "iron heart" means that Wang Jiyuan was determined to report the message quickly. In (11b), people with a golden heart always have precious characteristics.

While interacting with the outside world, people may map the features of the external things onto the human body parts in terms of cognition. As a result, relative bodily metaphorical expressions are derived. As one of the most visible features of the thing, color can be seen everywhere in our daily life, such as white wall, red flower, blue sky, etc. The "heart" and "xin" object also have this feature by means of metaphorical mapping. Here are some examples.

(12) a. 叶洪海在失败面前不灰[心]。

Ye Honghai did not lose heart(lit. grey-heart) in the face of failure.

b. Riggo was right when he said Dan has a'dark heart'. This guy will do anything for a buck. 
In (12a), “灰心” (lit. grey-heart), composed of the single words “灰”(grey) and “心” (heart), means losing heart or not having the power or willingness to do something. Such corresponding expression in English cannot be found. In (12b), people with a "dark heart" have an evil mind and are always vicious, jealous, and evil.

The "heart" and "xin" object can also be countable. In terms of metaphorical cognition, the "heart" combined with the number can express its quantity. Every human body has only one heart. If people do something with one whole heart, it means that they will try their best to finish it. Usually, they will succeed and things will be achieved. For example, there are expressions of “一心意 (lit. one-heart one-intention)” “全心全意(lit. whole-heart whole-intention)” in Chinese that means the same as the expressions of "put one's whole heart into something" in English. If the "xin" is divided into several parts to do something such as “三心二意” “一心二用”, it can only do something with divided attention or change their mind constantly.

(13) a. 孩子的祖母立即说了一句: “你不要多[心], 我们是将你当自己的女儿。”

The child's grandmother immediately said: "you don't have to be oversensitive (lit. many-hearts), we treat you as our own daughter."

b. Therefore I have no heart, and cannot love.

In (13a), a person with many hearts is oversensitive or thoughtful in Chinese. In (13b), westerners believe that the HEART IS THE SEAT OF EMOTIONS. Therefore, if they do not have a heart, they will not have any emotions, love is no exception.

（14）a.叔叔一片好[心], 赶来收养我们四个孤儿.

My kind-hearted uncle came to adopt us four orphans.

b. I believe that Michael was always innocent, because he truly had a good heart.

Example (14a) and (14b) shows that people with good hearts always have sterling qualities. In other words, the quality of heart represents the quality of person.

\subsubsection{Variation of the Conceptual Metaphors Denoting HEART in CCL and COCA}

Fauconnier (1994: 10) observes that there appears to be a lot of variation at different levels: "This implies possible variation from community to community, from context to context, from individual to individual". Metaphor is a universal cognitive phenomenon that fundamentally shapes the conceptual structures of people using different languages. However, the metaphorical human languages may also avail differences in actual use regardless of the universality of conceptual metaphor.

While many of the metaphors are shared on both lists (six out of the top ten metaphors are shared), these shared metaphors may rank differently in the respective lists. LIQUID, for example, ranks sixth in COCA while it is the fourth most frequently used metaphor in CCL. Further, FIRE ranks seventh on the American list while it is the sixth item on the Chinese list.

The AGRICULTURE domain is both used for the conceptualization of the HEART domain in English and Chinese, which ranks the 8th in CCL but not in the top ten in COCA. In other words, the AGRICULTURE metaphor is more elaborate in Chinese culture than in Western cultures.

In agrarian terms, the heart is the "ground, field, or soil" out of which the "seeds" of words and thoughts will grow into "plants" that will bear "grains" or "fruits" in due time. The place for botanic growth in the heart field is the place for mental and moral growth.

(15) a. 老师对孩子说话，不但是智慧的启迪，更是流淌着爱的清泉，滋润着孩子幼小的[心]田。

Teachers' talk to children is not only the inspiration of wisdom but also the spring of love, which moistens the young children's heart-field.

b. The faith, fear, and love are planted in the heart.

In (15a), while talking to Children, the teacher can bring them wisdom and show their love to the Children. In this way, Children will feel comfortable just like the dry field being moistened. In (15b), the "heart" is conceptualized as a "field" where "faith, fear, and love" are planted as seeds. 
The potentially universal metaphors may also display variation in their specific details. Some authors (see especially Kövecses (2005) have argued the existence of two different levels of conceptualization: a generic level of human embodied cognition and a more specific level of elaboration of these universal schemas. Conceptual variation, according to these researchers, would be limited to the second level. For example, although both English and Chinese use the same source domain of OBJECT WITH FLAVOR for HEART, there are still subtle differences. As can be seen in table 5, there are 32 Chinese examples but only 4 English examples that metaphorize the HEART as the OBJECT WITH FLAVOR. The 4 English examples respectively describe the "heart" as sweet, raw, sour, and spic. There are more data in CCL that emphasize the different flavors of "heart". "Heart" with different flavors represents the different feelings and emotions that people have. Some examples are as follows.

(16) a. 往事的回忆使他[心]酸。

Memories of the past saddened him (lit. make-him-heart-sour).

b. 听着这些既使人[心]酸, 又觉得有趣的故事, 我更加心疼和依恋他了。

Listening to these sad (lit. heart-sour) but interesting stories, I feel more distressed and attached to him.

c. 我也曾经憧憬过这样的婚姻, 一个我甘[心]奉献自己的人, 但是我至今没有遇到。

I have also looked forward to such a marriage, a person I am willing to (lit. sweet-heart) devote myself to, but I have not met so far.

d. 现在您明白了吧。我不甘[心]啊, 我真是不甘[心]!

Now you see. I'm not reconciled to (lit. sweet-heart) it. I'm really unwilling(lit.not-sweet-heart)!

e. 傅增寿的这番苦[心] 终于得到了回报, 半年后, 小李竟奇迹般地恢复了视力。

$\mathrm{Fu}$ Zengshou's painstaking efforts (lit. bitter-sweet) finally paid off. After half a year, Xiao Li miraculously recovered his eyesight.

f. 赛前, 音乐老师鴊费苦[心], 为他精选演唱曲目。

Before the competition, the music teacher took great pains to(lit. bitter-heart) select the songs for him.

g. You made it clear right from the start. I am to take your sour heart within one sad game.

h. When your heart is raw it is not ready to give up words or thoughts or express itself.

The "sour heart" in (16a) and (16b) represents the feelings of sadness. The "sweet heart" means that people are willing to do something, as exemplified by (16c) and (16d). In (16d), the Chinese character “不 bu" means "not", which is a negative word. Thus “不甘心(lit. not-sweet-heart)" means "being unwilling to do something”. The "bitter heart” in (16e) and (16f) implies the great efforts that people take in order to finish something. Example (16g) and (14h) are English data in COCA. The person with a "sour heart" in example $(16 \mathrm{~g})$ is jealous of others. This meaning is different from the "sour heart" in Chinese. The "raw heart" in (16h) implies that the person cannot provide a complete answer yet.

From the above examples, it can be seen that although the roughly same source domain is provided for the two languages, one language shows a preference for how the metaphor is employed specifically, and their frequency of use may be different.

There is another kind of metaphorical variation, which refers to the case where unique source domains are used for a specific target domain in different languages.

GAG is a case where a unique source domain is used for HEART in Chinese, which is the seventh most frequent conceptualization of HEART in CCL, accounting for $0.67 \%$ of the total data. However, these metaphorical expressions about HEART IS GAS could not be found in English.

In ancient China, the "gas" is the source of all lives in the whole world. Chinese people use the "gas" to describe some abstract entities, such as “脾气 temper (lit. spleen-gas)” “运气 luck (lit. move-gas)” “勇气 courage (lit. courageous gas)", etc. In Chinese culture, HEART sometimes is also considered as GAS, referring to something gaseous. To take “心气高(lit. heart-gas-high)” as an example, it is used to indicate "be proud and even arrogant”. For instance:

(17) a. 他[心]气高, 可天津卫是商埠, 毛笔是用来记帐的, 没人看书, 自然也没人燋。 
He is arrogant (lit. heart-gas-high), but Tianjin Wei is a commercial port, and the brush is used to keep accounts. No one reads books and naturally no one looks at it.

b. 村民们[心]气顺了, 问题解决了, 都忙于自己的事, 打架、上访、告状的少了。

The villagers are in a good mood (lit. heart-gas-smooth) and the problems are solved. They are busy with their own affairs. Thus there are fewer fights, petitions, and complaints.

c. 这一协议对港商[心]气有利, 使他们松了一口气。

This agreement is good for Hong Kong businessmen's heart gas and gives them a sigh of relief.

In (17a), when someone's heart is full of high gas, he is arrogant and haughty. In (15b), people feel relaxed when their heart gas can move smoothly. By contrast, they will feel depressed and worried when the movement of heart gas is blocked. In (17c), when something beneficial for the heart gas is done, people will feel happy and relaxed.

MECHANICS is another case where a unique source domain is used in the conceptualization of HEART in English, which ranks fourth in table 3. In mechanical terms, the heart is a "pump", an "engine", a "motor", a "spring" or a "wheel" that is part of a larger mechanical structure. As natural products of an age of industrialization propelled by the rapid development of science and technology in the west, such mechanics metaphors gave rise to the understanding of the heart as the "source of energetic forces" that are more "mechanical" than mental.

(18) a. My heart was beating like a jackhammer.

b. Essentially, the heart pumps blood to the head.

In (18a), if the beating heart was understood as a jackhammer, it means that the heart rate is very high. In (18b), the "heart" has been understood as a "pump" transporting vitality to all parts of the body through veins and arteries as its piping and plumbing system.

In short, table 2 and table 3 imply that the available source domains to both Chinese and American linguistic communities are generally the same. However, as shown in table 4 and table 5, some source domains are used more often in the respective linguistic communities, which results in people's different attitudes towards life. As a result, some conceptual metaphors gradually become more established and more entrenched.

\subsection{Factors Leading to the Universality and Variation}

Based on the above analysis, it can be found many similarities and differences that exist in the conceptualization of HEART in Chinese and English. The next section will be dedicated to answering the question: what leads to the similarities and differences?

\subsubsection{Factors Leading to the Universality}

As the results revealed above, six out of the ten top metaphors in CCL and COCA are shared. How is it possible that two such diverse languages and cultures share the same metaphors? Kövecses (2005: 35) has given some explanation for such commonalities. "It should come as no surprise that at least some conceptual metaphors can be and are found in many languages. If some kinds of conceptual metaphors are based on embodied experience that is universal, these metaphors should occur - at least potentially — in many languages and cultures around the world". In other words, there is some universal bodily experience in the two languages that leads to the emergence of the shared HEART metaphor.

To a great extent, the conceptual metaphors across human cultures are similar because human-beings have a similar body, face almost the same environment, and share the mutual experience, which lead to a similar pattern of conceptualization. It is not at all surprising that so many similar metaphorical expressions of heart in both languages are found. The universality of the conceptual metaphors has been discussed in 3.2.1.

As can be seen in table 2 and table 3, it is not difficult to find that the ontological metaphor is the most common type of the HEART metaphor in English and Chinese. The original way of human existence is material. People's experience of objects provides an important material basis for them to understand abstract concepts as "objects". The ontological metaphor is thus derived. In the ontological metaphor, people regard the abstract and intangible things as concrete and tangible objects so as to talk about, quantify them and identify their characteristics and causes. It is no wonder that the CONTAINER and OBJECT are shared source domains for the HEART in English and Chinese, and are the two most popularly used metaphor in both CCL and COCA. 
Embodiment provides a theoretical basis for the similarity between English and Chinese HEART metaphors. Because people of different nationalities or cultures have the same body structure, physiological characteristics, and perception experience, there are many similarities in human thinking and language. It also shows that experience and cognition play a fundamental and decisive role in language formation.

\subsubsection{Factors Leading to the Variation}

The conception of the human heart is an important and essential part of the conception of the human body. Our body, although such a fundamental and intimate thing to us, does not give rise to a uniform understanding. On the contrary, it invokes markedly different conceptions across languages. Now, the question to ask is: If there really is a difference between Chinese and English conceptualizations of the HEART, what caused this difference? The answer lies, it seems, in the different philosophical thought, the medical thought and different social-cultural history.

It is worth stressing that the experiential basis of conceptual metaphors is both bodily and cultural. The term "experience" by Lakoff and Johnson (1980: 57) covers culture, "we experience our 'world' in such a way that our culture is already present in the very experience itself." Synnott (1993: 262) concludes, "every culture constructs its own body differently". Gibbs (1999: 146) state as follows: "our understanding of what is conceptual about metaphor involves significant aspects of cultural experience, some of which is even intimately related to our embodied behavior." The language is but a part of the cultural system (Palmer, 1996). Manifested linguistically, the conceptualization of the "heart" is indeed a phenomenon at the cultural level of cognition (Sharifian, 2003). Metaphors are very often grounded in immediate bodily experience, but expand it through the mediating role of cultural models, such as those embodying ethnomedical/religious beliefs. As shown in example (17), GAS is a unique source domain for the Chinese HEART, which does not exist in English. GAS is represented by “气 qi" in Chinese. The theory of the qi, which originates in ancient Chinese philosophy, is an important theory in traditional Chinese medicine. As a philosophical concept, the qi generally refers to the most essential substance from which life begins and on which life depends on its substance. The five zang organs of the human body transform the extract from food into the qi whereas the qi strengthens the five zang organs and the body as a whole. Therefore, the qi is conceptualized as the material basis of human life with both physical and mental activities.

As shown in table 1, HEART metaphor in Chinese which accounts for $49.43 \%$ of the CCL data is richer than HEART metaphor in English with only $39.67 \%$ of the COCA data. This is not a coincidence, because the Chinese and English people have different philosophical thoughts. It is a case in which different cultural models interpret the functioning of the mind and the body differently. It seems that the English speaking people have two centers of themselves: heart and head. Heart is connected to feelings and emotions, especially with good emotions. Head refers to mind here, and it is connected with the ability to think and reason. So we can find expression like: keep in mind, make up your mind and so on, but in Chinese we express this meaning respectively this way: 记心里 keep in mind (lit. remember-heart-in), 下定决 心' make up your mind (lit. down-decide-determine-heart). Western culture's binary contrast between the heart and the mind does not exist in traditional Chinese culture. The Chinese heart is traditionally regarded as the seat of thought and feeling in ancient Chinese philosophy. According to traditional Chinese medicine, the heart is the "grand master of the five zang and six fu organs", presiding over all mental and emotional activities. This heritage of cultural conceptualization has been passed down to the present day. "Xin" covers the function of thought and feeling in presentday Chinese. However, Western dualism upholds the reason-emotion dichotomy. The "heart" in present-day English can only be conceptualized as feelings only. In other words, the "heart" and the "mind" in the Western senses are conceptualized in ancient Chinese philosophy as being one, the 心 xin "heart", which houses thoughts and feelings, ideas, and emotions.

As Radden and Panther (2004: 26) state: "Just as present-day human behavior is the result of past motivations, presentday language behavior (and we might add, the products of this behavior, language structures) is motivated by factors that were operative a long time ago but whose effects are still visible today". Different social history is another aspect that influences people's conceptualization of HEART in English and Chinese. As mentioned in example (18a) and (18b), there is a significant difference between Chinese and Western's conceptualization of the MECHANICS metaphor. With the advancement of western scientific knowledge in the early modern period, there has been a "mechanistic turn" in the understanding of the universe and the human body. Thus, the heart is understood as a variety of machine parts and components, such as "pumps", "engines", "mechanical springs", "wheels" or "clockwork". By contrast, the Chinese seem to lack the MECHANICS metaphor for the HEART. Therefore, the differences in the use of the HEART metaphors between Chinese and Western do reflect their social and historical differences. In China, a traditional agricultural country, industrialization was delayed a lot. It did not really take place until the 20th century. 
This social and historical difference can also explain why the AGRICULTURAL metaphor is more prevalent in Chinese than English.

In addition, the OBJECT WITH FLAVOR metaphor that is more prominent in CCL than in COCA is owing to the different cultural histories. In Chinese culture, where the cuisine is an important component, there are five basic flavors, which fall into the schematic pattern of the five elements: sweet, sour, bitter, pungent, and salty. The prominent position of cuisine in the mind of Chinese people can be explained by its history. The ruling class in Chinese history was able to eat well and enjoy well. They pay much attention to the color, smell, and flavor of food, the complexity of food processing, and the rich meaning of food, which is beyond any other culture in the world. Therefore, one has mixed "tastes" (and smells) of emotions, not in the mouth (or nose), but in the heart.

Discussed here as manifested in English and Chinese, the cultural conceptualizations of the "heart" are indeed constructed through their respective social and cultural histories and embedded within their respective philosophical and medical thought.

\section{Conclusions}

With data collected from CCL and COCA, this research compared HEART metaphor in Chinese and English and found out that there are both universalities and variations of HEART metaphor in Chinese and English. Reasons for the universalities and variations are further summarized as follows.

Due to the universal bodily experience, many source domains are shared for the target domain of HEART. The top three shared source domains in English and Chinese are respectively CONTAINER, OBJECT, and LIVING ORGANISM.

As for the variations, there are cross-cultural differences in the frequency of use of the HEART metaphor in English and Chinese owing to the different philosophical thought. In addition, the frequency of the shared metaphors may display variations in their specific details (e.g., OBJECT WITH FLAVOR) on account of the different cultural histories. Finally, GAS in Chinese and MECHANICS in English are unique source domains for HEART, which respectively are ascribed to the traditional Chinese medicine and the different social-cultural history between Chinese and English.

However, the main constraints in mentioning the study should still be addressed. For one thing, the collection of the corpora concerning HEART in English and Chinese is limited. Thus, the results of the HEART metaphor may be not exhaustive.For another, though this paper adopts the MIP method to increase the credibility of results, much identification and classification are subjective to the researchers to some extent. Therefore, further research is necessary to adopt a more comprehensive and objective method in order to guarantee the results.

\section{Acknowledgments}

The study has been supported by Jiangxi Provincial Department Innovation Foundation for Postgraduates---CorpusBased Contrastive Study of HEART Metaphor in English and Chinese (YC2020-S193).

\section{References}

Brdar-Szabo,R., \& Mario, B. (2012). The problem of data in the cognitive linguistic research on metonymy: a crosslinguistic perspective. Language Sciences,34, 728-745.

Doueihi, M. (1997). A Perverse History of the Human Heart. Cambridge, MA: Harvard University Press.

Fauconnier, G. (1994). Mental Spaces. Aspects of Meaning Construction in Natural Language. Cambridge: Cambridge University Press.

Foolen, A. (2008). The heart as a source of semiosis: the case of Dutch. In Farzad Sharifian, René Dirven, Ning Yu, and Susanne Niemeier (Eds.), Culture, Body, and Language: Conceptualizations of Internal Body Organs across Cultures and Languages, (pp.373-390). Berlin/New York: Mouton de Gruyter.

Gibbs, R, W. (1999). Taking metaphor out of our heads and putting it into the cultural world. In Raymond W. Gibbs and Gerard J. Steen (Eds), Metaphor in Cognitive Linguistics, (pp.145-166). Amsterdam/Philadelphia: John Benjamins Publishing Company.

Goddard, C. (2008). Contrastive semantics and cultural psychology: English Heart vs. MalayHati.In Farzad Sharifian, René Dirven, Ning Yu, and Susanne Niemeier (Eds.),Culture, Body, and Language---Conceptualization of Internal Body Organs across Cultures and Languages. Berlin/ New York: Mount de Gruyter.

Høystad, O, M. (2007). A History of the Heart (John Irons, Trans). London: Reaktion Books.

Johnson, M. (2007). The Meaning of the Body: Aesthetics of Human Understanding. Chicago: University of Chicago Press. 
Johnson, M., \& Tim P. (2007). We are live creatures: embodiment, American pragmatism and the cognitive organism. InTom Ziemke, Jordan Zlatev, and Roslyn M. Frank (Eds.), Body, Language and Mind (Vol. 1): Embodiment, (pp.17-54). Berlin/New York: Mouton de Gruyter.

Kövecses, Z. (2005). Metaphor in Culture: Universality and Variation. Cambridge: Cambridge University Press.

Lakoff, G., \& Johnson, M. (1980). Metaphors We Live By. Chicago: University of Chicago Press.

Lakoff, G., \& Johnson, M. (1999). Philosophy in the Flesh: The Embodied Mind and Its Challenge to Western Thought. New York: Basic Books.

Palmer, G, B. (1996). Toward a Theory of Cultural Linguistics. Austin, TX: University of Texas Press.

Pritzker, S. (2007). Thinking hearts, feeling brains: metaphor, culture, and the self in Chinese narratives of depression. Metaphor and Symbol, 22, 251-274.

Radden, G., \& Panther, K. (2004). Introduction: Reflections on motivation. In G. Radden and K.-U. Panther (Eds.), Studies in Linguistic Motivation (pp.1-46). Berlin \& New York: Mouton de Gruyter.

Reddy, M. (1979). The conduit metaphor---a case frame conflict in our language about language. In A. Ortony (ed.), Metaphor and Thought, 1st ed., 228-324. Cambridge and New York: Cambridge University Press.

Sharifian, F. (2003). On cultural conceptualizations. Journal of Cognition and Culture, 3, 187- -207.

Susanne, N. (2000). Straight from the heart: metonymic and metaphorical explorations. In Andrew Barcelona (Ed.), Metaphor and Metonymy at the Crossroads: A Cognitive Perspective (pp.193-213). Mouton de Gruyter, Berlin.

Susanne, N. (2008). To be in control: kind-hearted and cool-headed. The head-heart dichotomy in English. In Farzad Sharifian, René Dirven, Ning Yu, and Susanne Niemeier (Eds.), Culture, Body, and Language: Conceptualizations of Internal Body Organs across Cultures and Languages, (pp.349-372). Mouton de Gruyter, Berlin.

Synnott, A. (1993). The Body Social: Symbolism, Self, and Society. London/New York: Routledge.

Yu N. (2007). Heart and cognition in ancient Chinese philosophy. Journal of Cognition and Culture, 7, 27-47.

Yu, N. (2009). The Chinese HEART in a Cognitive Perspective: Culture, Body, and Language. Berlin/ New York: Mouton de Gruyter.

Qi, Z., \& Wang, Y. (2007). The cognitive framework of the word "HEART". Foreign Languages Research, 1, 61-66.

Wang, W. (2001). On the structure of the spatial metaphor of the Chinese HEART. Journal of PLA Foreign Languages Institute, 1, 57-60.

$\mathrm{Wu}$, E. (2004). On the metaphorical cognitive system of Chinese HEART. Language Teaching and Linguistic Studies, $6,49-55$.

Xiang, D. (2010). Cognitive analysis of the "HEART IS THE RULER" metaphor. Language Teaching and Linguistic Studies, 1, 80-87.

Xie, Z., \& Shi, T. (2007). Comparison of semantic category transfer between English and Chinese HEART. Shandong Foreign Languages Teaching Journal, 4, 30-35.

Zhang, J. (2005). The polysemous network of Chinese HEART: metonymy and metaphor. Rhetoric Learning, 1, 40-43.

Zhang, J. (2006). A comparison of polysemous networks of HEART in English and Chinese. Journal of Zhejiang University (Humanities and Social Sciences Edition), 3, 161-168. 